\title{
Silicon induced physiological and biochemical changes under polyethylene glycol-6000 water deficit stress in wheat seedlings
}

Authors Info

S. S. Sapre* and D. N. Vakharia ${ }^{2}$

${ }^{1}$ College of Agriculture, Junagadh Agricultural University, Amreli-365 601, India

${ }^{2}$ Department of Biochemistry, College of Agriculture, Junagadh Agricultural University, Junagadh-362 001, India

${ }^{*}$ Corresponding Author Email : srngsapre27@gmail.com

Key words

Antioxidative enzymes,

Oxidative stress,

Silicon,

Wheat seedling

Publication Info

Paper received : 21.11 .2015

Revised received: 06.05 .2016

Re-revised received : 30.07 .2016

Accepted: 12.09 .2016

\section{Abstract}

Aim: The experiment was conducted to study the role of foliar application of silicon $\left(\mathrm{SiO}_{2}\right)$ under water deficit stress in wheat seedling stage by evaluating the physiological and biochemical parameters.

Methodology: Application of silicon was made on $7^{\text {th }}$ and $14^{\text {th }}$ days after germination (DAG) to the seedlings of wheat (Triticum aestivum L.) varieties followed by imposition of polyethylene glycol- 6000 (PEG) induced stress on $15^{\text {th }}$ DAG. The samples were analyzed after 24 hours for relative water content (RWC), membrane stability index (MSI), total chlorophyll, proline, malondialdehyde (MDA), peroxidase (POX), catalase (CAT) and silicon content.

Results: Application of silicon followed by water deficit conditions increased RWC compared to PEG stress. There was a meagre percent variation in $\mathrm{MSI}$ in $\mathrm{SiO}_{2}$ and $\mathrm{SiO}_{2}+\mathrm{PEG}$ treatments as compared to PEG and control. The $\mathrm{SiO}_{2}$ treatment enhanced antioxidative enzymes in most cases. Positive correlations $(P<0.01)$ were observed between enzymatic antioxidants, RWC and MSI, while MDA and proline displayed positive correlation $(P<0.01)$. Silicon was able to ameliorate stress conditions as reflected by a significant rise in RWC $(17.69 \%)$, MSI $(55.80 \%)$, antioxidant enzyme level i.e. POX $(77.97 \%)$, CAT $(89.32 \%)$ and a significant decline in proline content (36\%).

Interpretation: The foliar silicon treatment can be used as a promising alternative to mitigate water stress induced damage in wheat seedlings.

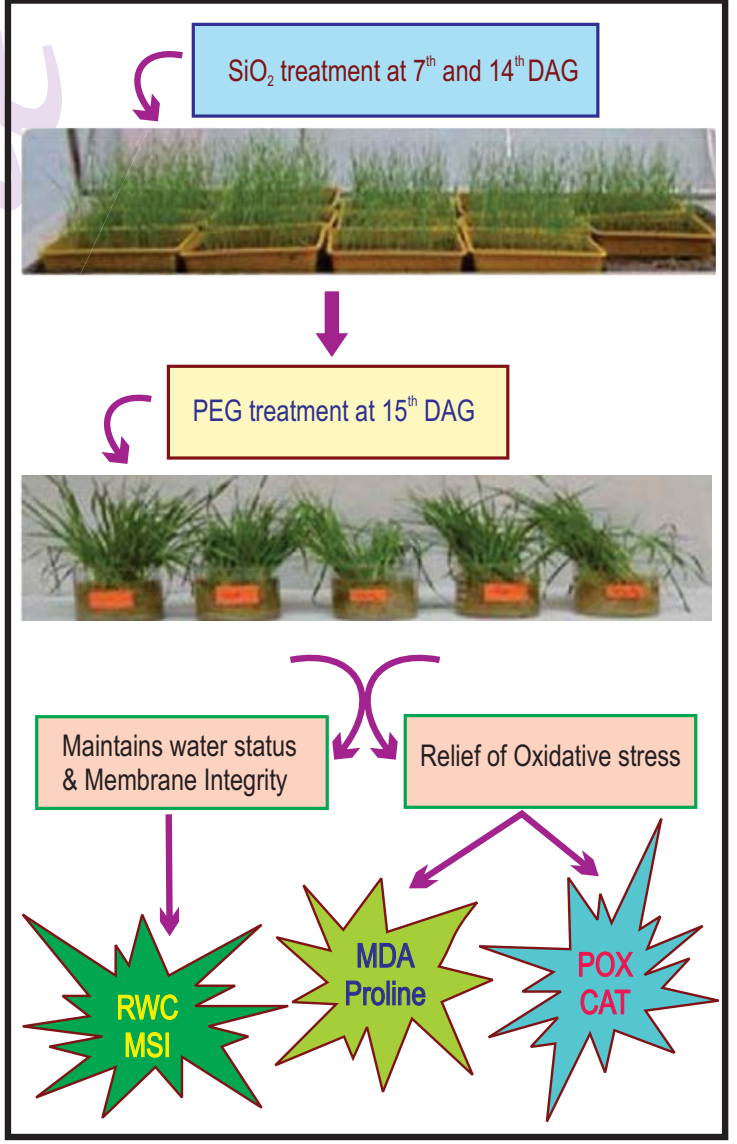




\section{Introduction}

Wheat is the dominant food grain of the world. India stands second in the world after China in terms of production. Water stress usually shortens the life cycle and grain-filling period of crops, reducing photosynthesis and accelerating senescence (Stoilova et al., 2009). There is a relationship between different physiological responses of crops and their tolerance functions under drought such as high amount of relative water and water potential and integrity of membrane (Nezhadahmadi et al., 2013). Drought stress leads to biochemical response such as transient decrease in photochemical efficiency, accumulation of stress metabolites, increase in antioxidative enzyme activity and reduced reactive oxygen species accumulation (Reddy et al., 2004).

Silicon is probably the only element which is able to enhance tolerance to multiple stresses. Its beneficial effects under water deficit conditions can be associated with increase in action of antioxidant mechanisms, a reduction of oxidative damage to functional molecules and membranes and maintenance of many of the physiological processes such as improvement of plant water status (Mauad et al., 2016; Sacala, 2009). Even though wheat is considered as a silicon accumulating crop, its supply may alleviate damaging effects that result from drought. Silicon is considered immobile in phloem and redistribution of silicon in plant is very low (Pilon et al., 2013). Taking this point into consideration, foliar application using small amount of silicon can be a practical alternative to soil uptake and stimulate its beneficial effects (Wang and Galleta, 1998). Most of the study has been performed by either applying silicon in soil (i.e. root-derived), or supplemented in nutrient medium; very few studies are in relation with foliar application of silicon viz. in potato by Pilon et al. 2013 in maize (Sayed and Gadallah, 2014). A recent study by Pilon et al. (2014) in potato revealed that foliar-applied silicon positively influenced the osmotic adjustment, antioxidant enzymes activities in leaves of water-stressed potato plants. In view of the above points, a physiological and biochemical study was carried out to evaluate the role of foliar application of silicon under water deficit stress in different wheat varieties at seedling stage.

\section{Materials and Methods}

The present investigation was conducted during the rabi (winter) season in the year 2012. It comprised of ten bread wheat (Triticum aestivum L.) varieties; GW-496, GW-366, GW-322, GW190, GW-173, LOK-1, DL-788-2, HD-2932, RAJ-4083 and HI1563 which were procured from the Wheat Research Station, Junagadh Agricultural University, Junagadh, Gujarat, India.

Experimental conditions : Sixty seedlings of each variety were grown in sand culture in a plastic tray $(40 \times 28 \times 7 \mathrm{~cm})$. Total of 120 trays were used for various treatment combinations. The trays were protected by a net covering and were watered periodically. Silicon was applied as $\mathrm{SiO}_{2}$ (silicon dioxide) in the study; whereas water stress was imposed using PEG-6000 (polyethylene glycol). There were four treatments comprising of treatment $T_{1}$ : (control viz. no PEG and $\left.\mathrm{SiO}_{2}\right) ; \mathrm{T}_{2}$ : (20\% PEG only); $\mathrm{T}_{3}$ : (1.5 $\mathrm{mM} \mathrm{SiO}_{2}$ only) and $\mathrm{T}_{4}$ : $\left(1.5 \mathrm{mM} \mathrm{SiO}_{2}+20 \%\right.$ PEG). The optimized levels of PEG and $\mathrm{SiO}_{2}$ was selected from a preliminary experiment based on shoot, root length and seedling fresh weight [data not shown]. A foliar treatment of $1.5 \mathrm{mM}$ silicon was given on $7^{\text {th }}$ and $14^{\text {th }}$ day after germination. Spraying was done with a sprayer in the morning hours until leaf run-off. On the $15^{\text {th }}$ day, sand was flooded with water and 20 seedlings were pulled gently without damaging the roots. Excess of sand attached to the roots was washed off. The seedlings were then placed in $100 \mathrm{ml} 20 \%$ PEG solution in a 250 $\mathrm{ml}$ beaker for $24 \mathrm{hrs}$ (Garg et al., 2012). Unstressed treatments $\left(T_{1}\right.$ and $\left.T_{3}\right)$ were kept similarly in water for the same time period. After $24 \mathrm{hrs}$, the physiological and biochemical parameters were analyzed in three replicates.

Physiological parameters : The methods described by Weatherley (1950) and Blum (1981) were used for determination of relative water content (RWC) and membrane stability index (MSI), respectively. MSI was calculated by the following formula $\left(1-\left(C_{1} / C_{2}\right)\right) \times 100$, where $C_{1}$ is the electric conductivity of samples at $40^{\circ} \mathrm{C}$ for $30 \mathrm{~min}, \mathrm{C}_{2}$ is the Electric conductivity of samples at $100^{\circ} \mathrm{C}$ for $10 \mathrm{~min}$. Total chlorophyll content was measured by non-maceration method of Hiscox and Israelstam (1979). It was calculated by the formula: Total chlorophyll $\left(\mathrm{mg} \mathrm{g}^{-1}\right)=22.2$ (O.D. at $645 \mathrm{~nm})+8.02($ O.D. at $663 \mathrm{~nm}) \times(\mathrm{V} / \mathrm{W})$; where $\mathrm{V}$ is the volume and $W$ is the weight.

Oxidative stress parameters : Proline concentration was determined by the method of Bates (1973). Approximately, of $0.3 \mathrm{~g}$ leaf tissue was homogenized in $5 \mathrm{ml}$ of $10 \%$ sulphosalicylic acid and the homogenate was centrifuged at $8,000 \mathrm{rpm}$ for $10 \mathrm{~min}$. For malondialdehyde (MDA) content, the leaves were homogenized in $5 \mathrm{ml}$ of $0.1 \%$ trichloroacetic acid. The homogenates were centrifuged at $8,000 \mathrm{rpm}$ for $15 \mathrm{~min}$. The concentration of thiobarbituric acid reactive substances (TBARS) was calculated using an extinction coefficient of $155 \mathrm{mmol}^{-1} \mathrm{~cm}^{-1}$ (Heath and Packer, 1968). Autoclave induced digestion method (AID) was carried out for estimating silicon content from the dried leaves (Elliot and Snyder, 1991). The absorbance was measured at $650 \mathrm{~nm}$ and the silicon standard was prepared with sodium silicate, which contained $1 \mathrm{mg} \mathrm{ml}^{-1}$ silicon.

Antioxidant enzymes: The enzyme extract was prepared by grinding $0.2 \mathrm{~g}$ of leaf material with $5 \mathrm{ml}$ of chilled $0.1 \mathrm{M}$ phosphate buffer ( $\mathrm{pH} 7.0)$ in a prechilled mortar and pestle. This crude enzyme extract was analyzed immediately for peroxidise (POX) and catalase (CAT) activity. The POX activity was determined using orthodianisidine dye and change in the colour of the oxidized dye was read at $460 \mathrm{~nm}$ (Bisswanger, 2011). CAT activity was estimated following the method of Aebi (1984). Enzyme 
activity was measured as $\Delta O D / m g$ protein $/ \mathrm{min}$. Protein was determined by Lowry's method (Lowry et al., 1951).

Statistical analysis : The experimental data was laid out in twofactor (variety, treatment) factorial arrangement under a completely randomized design. The data was analyzed using OPSTAT software, Statistical package for agricultural workers (http://hau.ernet.in/about/opstat.php). Pearson correlation coefficients for all the parameters were carried out using SPSS 16.0 version

\section{Results and Discussion}

Relative water content strongly reflects the balance between water supply to the leaf and transpiration. The highest RWC was recorded in variety GW366 followed by GW190, whereas HD2932 followed by RAJ4083 showed the lowest RWC. Treatment $T_{2}$ (PEG) recorded the lowest RWC which increased significantly (17.69\%) on imposition of treatment $\mathrm{T}_{4}\left(\mathrm{SiO}_{2}+\mathrm{PEG}\right)$ (Table 1). On considering the interaction effect, the seedlings grown with treatment $\mathrm{T}_{3}\left(\mathrm{SiO}_{2}\right)$ showed highest RWC. Varieties RAJ4083 and GW496 showed greatest reduction (44.78 and $40.72 \%$ respectively) for water deficit treatment and control comparison. The least percent decrease was observed in varieties LOK1, GW190 and GW366 on comparison of treatment $\mathrm{T}_{4}\left(\mathrm{SiO}_{2}+\mathrm{PEG}\right)$ and $\mathrm{T}_{3}\left(\mathrm{SiO}_{2}\right)$. Application of water deficit stress resulted in reduction of $\mathrm{RWC}$ which was relieved by $\mathrm{SiO}_{2}$ treatment (Table 1). The beneficial effect may be due to reduced transpiration (Gao et al., 2006); enhanced water uptake ability (Ahmed etal., 2011).

Membrane stability is widely used criterion to assess crop drought tolerance, since water stress caused by water loss from plant tissues seriously impairs both membrane structure and function (Buchanan et al., 2002). The highest value of MSI was found in GW173, while lowest MSI was recorded in GW 496 (Table 1). Water deficit stress resulted in highly significant reduction in $\mathrm{MSI}$ which was ammeriolated by $\mathrm{SiO}_{2}$. For the combined effect of variety and treatments $(V \times T)$, the lowest value of MSI was found in treatment $T_{2}$ (PEG) (Table 1). The percent reduction in $\mathrm{MSI}$ for $\mathrm{SiO}_{2}$ treated stressed seedlings $\left(\mathrm{T}_{4}\right)$ as compared with $\mathrm{SiO}_{2}\left(\mathrm{~T}_{3}\right)$ treatment was less in most varieties than the PEG treated $\left(T_{2}\right)$ seedlings and control $\left(T_{1}\right)$. The highest percent reduction was noted in variety GW496 $(69.36 \%)$ and HI1563 (62.50\%), whereas least percent decline was observed in GW190 (12.18\%) and GW366 (12.41\%) on comparing treatment $\mathrm{T}_{3}$ and $\mathrm{T}_{4}$. Sairam et al. (2002) reported that during stress there was a decrease in MSI irrespective of the genotypes. Geravandi et al. (2011) demonstrated that drought tolerant genotypes contained higher $\mathrm{MSI}$ as compared to drought sensitive genotypes. Application of silicon in the study, helped in the maintenance of membrane integrity, thereby reducing the damage caused by water deficit stress as also suggested by Shen et al. (2010); Sayed and Gadallah (2014).

Amongst the varieties, GW173 recorded highest chlorophyll content, followed by GW190 and GW322. The lowest chlorophyll content was found in LOK1, DL788-2 followed by GW496. A non-significant rise in chlorophyll content was recorded in treatments $T_{2}, T_{3}$ and $T_{4}$ as compared to control (Table 1). Maximum percent decrease in chlorophyll content under stress condition was observed in GW366 followed by DL788-2, LOK1 and GW322. Treatment $\mathrm{T}_{3}\left(\mathrm{SiO}_{2}\right)$ resulted in rise in

Table 1 : Values of relative water content (RWC), membrane stability index (MSI), total chlorophyll and interaction of varieties (V) and treatments (T) in wheat seedling

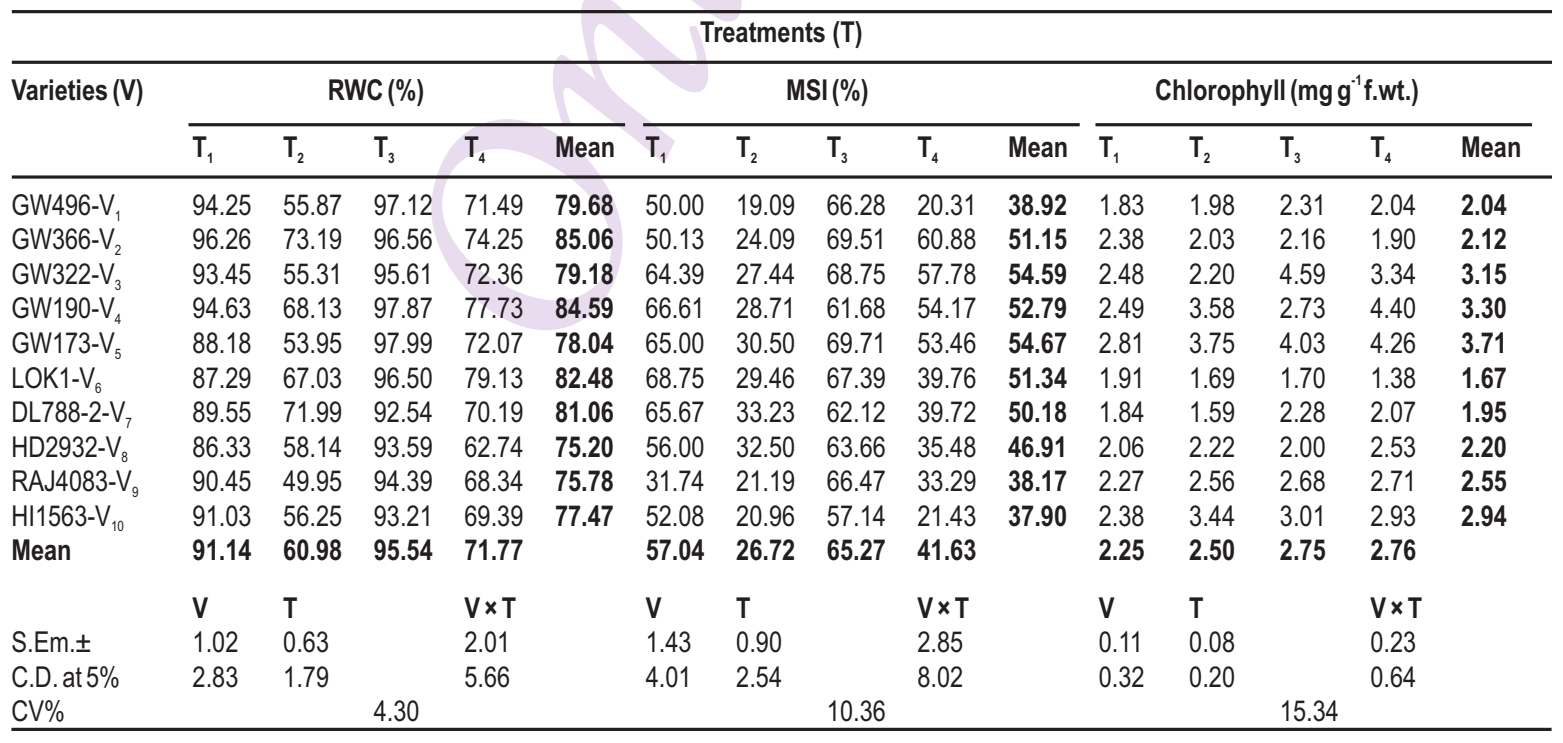


chlorophyll content as compared to control in most of the varieties, except GW366, LOK1 and HD2932. In the present study, a slight increase in chlorophyll content was observed upon imposition of water deficit conditions. Similar results were reported by Shen et al. (2010) in soyabean seedlings. Increase in total chlorophyll content in response to drought stress indicates that cell growth is more sensitive to water shortage than chlorophyll synthesis, thus smaller leaf cells resulted in higher chlorophyll content per unit leaf fresh weight (Valifard et al., 2012).

Proline accumulation during osmotic stress is mainly due to increased synthesis and reduced degradation. Highest proline content was found in variety GW496, while the lowest content was found in variety LOK1. Treatment $T_{2}$ (PEG) resulted in highest proline content which was significantly reduced upon incorporation of $\mathrm{SiO}_{2}$ (Table 2). Considering the interaction effect maximum fold rise in proline was noticed in varieties GW496 (63.39) and GW190 (41.05); when treatment $T_{3}$ (PEG) and $T_{1}$ (control) were considered. A rise in proline content along with increase in moisture deficit stress has been reported by Kumari and Sairam (2013). Although there is a positive correlation between drought tolerance and accumulation of proline content, contrary reports viz. Lutts et al. (1999) have related proline accumulation with salt-stress damage. Silicon induced decrease in proline accumulation as a sign of stress injury relief has been reported by Pei et al. (2010).

MDA content is an indicator of membrane damage. Maximum MDA content was recorded in HI1563, while lowest value was found in variety DL788-2 followed by GW366 (Table 2). Water deficit stress caused a significant increase in MDA content. However, $\mathrm{SiO}_{2}$ treatment under stress conditions revealed a non- significant decrease in MDA levels. For the combined effect of $\mathrm{V} \times \mathrm{T}$, highest range of MDA content was observed in PEG treatment, while lowest content was found in $\mathrm{SiO}_{2}$ treatment (Table 2). The highest fold increase was recorded in variety GW496 (4.40) upon comparison of treatments $\mathrm{T}_{4}\left(\mathrm{SiO}_{2}+\mathrm{PEG}\right)$ and $\mathrm{T}_{3}\left(\mathrm{SiO}_{2}\right)$. In support to the above findings, several reports have been made stating drought induced rise in MDA content in wheat (Sairam and Srivastava, 2001; Garg et al., 2012).

The highest silicon content was obtained in variety HD2932 followed by LOK1, while lowest values was obtained in GW190, GW366 (Table 2). Silicon accumulation increased in treatment $\mathrm{T}_{3}\left(\mathrm{SiO}_{2}\right)$ as compared to $\mathrm{T}_{1}$ (control). Silicon content decreased in stress treatments irrespective of its application in most of the cases. The highest percent reduction in silicon content was observed in variety RAJ4083 when $\mathrm{SiO}_{2}+\mathrm{PEG}\left(\mathrm{T}_{4}\right)$ was compared with $\mathrm{SiO}_{2}\left(\mathrm{~T}_{3}\right)$. Pilon et al. (2013) reported that both soil and foliar applied Si- treatments promoted higher silicon accumulation in potato plants. Soratto et al. (2012) stated that silicon leaf application efficiently supplied silicon for wheat plants. In the present study, silicon content increased due to silicon application regardless of the water regime as revealed by Chen et al. (2011).

The highest POX enzyme activity was recorded in HD2932 followed by GW190, whereas minimum activity was recorded in $\mathrm{GW}_{496}$. $\mathrm{SiO}_{2}$ treatment significantly raised the $\mathrm{POX}$ activity against control, as well as under stress conditions (Table 3). In terms of interaction effect, maximum POX activity was found in treatment $\mathrm{T}_{3}\left(\mathrm{SiO}_{2}\right)$, whereas minimum activity was recorded in treatment $\mathrm{T}_{2}$ (PEG). When $\mathrm{SiO}_{2}$ was applied along with PEG, highest percent increase in activity was recorded in GW366

Table 2 : Values of proline, malondialdehyde (MDA), silicon and interaction of varieties $(V)$ and treatments $(T)$ in wheat seedling

\begin{tabular}{|c|c|c|c|c|c|c|c|c|c|c|c|c|c|c|c|}
\hline \multirow{3}{*}{ Varieties } & \multirow{2}{*}{\multicolumn{5}{|c|}{ Proline (mg g ${ }^{-1}$ f.wt.) }} & \multirow{2}{*}{\multicolumn{5}{|c|}{$\begin{array}{r}\text { Treatments } \\
\text { MDA (mr }\end{array}$}} & & & & & \\
\hline & & & & & & & & & & & \multicolumn{5}{|c|}{ Silicon (mg g ${ }^{-1}$ d.wt.) } \\
\hline & $\mathrm{T}_{1}$ & $\mathrm{~T}_{2}$ & $\mathrm{~T}_{3}$ & $\mathrm{~T}_{4}$ & Mean & $\mathbf{T}_{1}$ & $\mathrm{~T}_{2}$ & $\mathrm{~T}_{3}$ & $\mathrm{~T}_{4}$ & Mean & $\mathrm{T}_{1}$ & $\mathrm{~T}_{2}$ & $\mathbf{T}_{3}$ & $\mathrm{~T}_{4}$ & Mean \\
\hline GW496-V & 0.04 & 2.42 & 0.06 & 1.37 & 0.97 & 1.13 & 4.61 & 0.75 & 3.30 & 2.45 & 3.40 & 3.00 & 6.89 & 7.38 & 5.17 \\
\hline GW366-V & 0.05 & 1.28 & 0.06 & 0.76 & 0.54 & 1.27 & 4.05 & 0.93 & 2.75 & 2.25 & 3.10 & 3.20 & 5.69 & 4.05 & 4.01 \\
\hline GW322-V & 0.05 & 1.18 & 0.08 & 1.47 & 0.69 & 1.50 & 3.78 & 0.95 & 3.62 & 2.46 & 2.70 & 3.35 & 6.23 & 5.33 & 4.40 \\
\hline GW190-V & 0.05 & 2.21 & 0.12 & 1.22 & 0.90 & 1.56 & 4.75 & 1.03 & 3.87 & 2.80 & 3.20 & 2.40 & 6.55 & 3.89 & 4.01 \\
\hline GW173-V & 0.08 & 2.41 & 0.07 & 1.09 & 0.91 & 1.70 & 2.46 & 1.91 & 4.08 & 2.54 & 4.15 & 3.09 & 6.40 & 6.20 & 4.96 \\
\hline LOK1-V $_{6}$ & 0.08 & 1.06 & 0.06 & 0.70 & 0.48 & 1.44 & 4.13 & 1.59 & 2.92 & 2.52 & 6.30 & 5.40 & 7.33 & 4.65 & 5.92 \\
\hline DL788-2-V & 0.06 & 1.76 & 0.07 & 0.76 & 0.66 & 1.12 & 1.70 & 1.07 & 2.85 & 1.68 & 4.20 & 3.05 & 6.81 & 4.94 & 4.75 \\
\hline HD2932-V & 0.06 & 0.95 & 0.05 & 1.21 & 0.57 & 1.80 & 3.16 & 1.65 & 3.95 & 2.64 & 6.20 & 3.90 & 8.54 & 5.10 & 5.93 \\
\hline RAJ4083-V & 0.07 & 1.08 & 0.06 & 1.09 & 0.58 & 1.75 & 3.27 & 1.83 & 4.11 & 2.74 & 5.05 & 4.05 & 6.75 & 3.96 & 4.95 \\
\hline HI1563- $V_{10}$ & 0.08 & 2.02 & 0.11 & 0.84 & 0.76 & 1.64 & 4.62 & 1.88 & 3.70 & 2.96 & 5.05 & 4.15 & 4.44 & 3.55 & 4.29 \\
\hline \multirow[t]{2}{*}{ Mean } & 0.06 & 1.64 & 0.07 & 1.05 & & 1.49 & 3.65 & 1.34 & 3.52 & & 4.33 & 3.56 & 6.56 & 4.90 & \\
\hline & V & $T$ & & $V \times T$ & & V & $\mathrm{T}$ & & $V \times T$ & & V & $\mathrm{T}$ & & $V \times T$ & \\
\hline SE & 0.06 & 0.04 & & 0.12 & & 0.09 & 0.06 & & 0.19 & & 0.18 & 0.11 & & 0.36 & \\
\hline C.D. at $5 \%$ & 0.17 & 0.11 & & 0.35 & & 0.26 & 0.16 & & 0.53 & & 0.51 & 0.32 & & 1.02 & \\
\hline CV\% & & & 30.30 & & & & & 13.17 & & & & & 12.99 & & \\
\hline
\end{tabular}


Table 3: Values of peroxidise (POX), catalase (CAT) and interaction of varieties (V) and treatments (T) in wheat seedling

\begin{tabular}{|c|c|c|c|c|c|c|c|c|c|c|}
\hline \multicolumn{11}{|c|}{ Treatments } \\
\hline \multirow[t]{2}{*}{ Varieties } & \multicolumn{5}{|c|}{$\operatorname{POX}\left(\triangle \mathrm{OD} \cdot \mathrm{mg}^{-1}\right.$ protein. $\left.\mathrm{min}^{-1}\right)$} & \multicolumn{5}{|c|}{ CAT $\left(\triangle O D \cdot \mathrm{mg}^{-1}\right.$ protein $\left.\cdot \mathrm{min}^{-1}\right)$} \\
\hline & $\mathrm{T}_{1}$ & $\mathrm{~T}_{2}$ & $\mathrm{~T}_{3}$ & $\mathrm{~T}_{4}$ & Mean & $\mathrm{T}_{1}$ & $\mathrm{~T}_{2}$ & $\mathrm{~T}_{3}$ & $\mathrm{~T}_{4}$ & Mean \\
\hline GW496-V & 15.60 & 13.94 & 22.84 & 27.10 & 19.87 & 1.84 & 1.43 & 3.60 & 2.53 & 2.35 \\
\hline GW366-V & 16.94 & 12.78 & 32.12 & 31.86 & 23.43 & 2.81 & 1.98 & 3.33 & 2.58 & 2.67 \\
\hline GW322-V $V_{3}$ & 20.85 & 15.85 & 50.13 & 24.55 & 27.84 & 1.68 & 1.61 & 4.94 & 4.18 & 3.10 \\
\hline GW190-V & 24.54 & 16.20 & 40.75 & 36.25 & 29.44 & 2.38 & 2.41 & 5.01 & 3.73 & 3.38 \\
\hline GW173-V & 17.97 & 15.69 & 29.46 & 36.00 & 24.78 & 2.32 & 1.60 & 3.65 & 3.44 & 2.75 \\
\hline $\mathrm{LOK}_{1}-\mathrm{V}_{6}$ & 18.38 & 11.92 & 35.67 & 29.43 & 23.85 & 3.32 & 2.32 & 3.92 & 4.92 & 3.62 \\
\hline DL788-2-V & 26.82 & 22.17 & 33.26 & 19.86 & 25.53 & 2.83 & 1.49 & 4.17 & 3.54 & 3.01 \\
\hline HD2932-V & 24.76 & 18.50 & 47.05 & 28.22 & 29.63 & 2.63 & 1.75 & 3.83 & 3.23 & 2.86 \\
\hline RAJ4083-V & 23.50 & 15.55 & 29.88 & 21.07 & 22.50 & 2.33 & 1.72 & 4.46 & 2.08 & 2.65 \\
\hline HI1563-V & 24.70 & 9.45 & 36.70 & 16.38 & 21.81 & 1.65 & 1.46 & 4.69 & 3.46 & 2.82 \\
\hline \multirow[t]{2}{*}{ Mean } & 21.41 & 15.21 & 35.79 & 27.07 & & 2.38 & 1.78 & 4.16 & 3.37 & \\
\hline & V & $T$ & & $V \times T$ & & v & $T$ & & $V \times T$ & \\
\hline SE & 0.58 & 0.37 & & 1.16 & & 0.10 & 0.06 & & 0.20 & \\
\hline C.D. at $5 \%$ & 1.63 & 1.03 & & 3.25 & & 0.28 & 0.18 & & 0.56 & \\
\hline CV\% & & & 8.05 & & & & & 11.90 & & \\
\hline
\end{tabular}

Table 4 : Pearson correlation coefficients between studied traits in wheat varieties under water deficit stress

\begin{tabular}{|c|c|c|c|c|c|c|c|c|}
\hline & RWC & MSI & Chlorophyll & Proline & MDA & Silicon & POX & CAT \\
\hline RWC & 1.000 & & & & & & & \\
\hline MSI & $0.83^{* *}$ & 1.000 & & & & & & \\
\hline Chlorophyll & $-0.05^{\mathrm{NS}}$ & $0.10^{\mathrm{NS}}$ & 1.000 & & & & & \\
\hline Proline & $-0.86^{* *}$ & -0.76 & $0.19^{\mathrm{NS}}$ & 1.000 & & & & \\
\hline MDA & $-0.82^{* *}$ & -0.74 & $0.20^{\mathrm{NS}}$ & $0.80^{*}$ & 1.000 & & & \\
\hline Silicon & $0.24^{\mathrm{NS}}$ & $0.15^{\mathrm{NS}}$ & $-0.35^{*}$ & $-0.30^{\mathrm{NS}}$ & $-0.21^{\mathrm{NS}}$ & 1.000 & & \\
\hline POX & 0.54 & $0.62^{+*}$ & $0.25^{\mathrm{NS}}$ & $-0.45^{*}$ & $-0.42^{*+}$ & $-0.11^{\mathrm{NS}}$ & 1.000 & \\
\hline CAT & $0.52^{*}$ & $0.55^{\circ}$ & $0.22^{\text {NS }}$ & $-0.44^{* *}$ & $-0.32^{\circ}$ & $-0.18^{N S}$ & $0.74^{* *}$ & 1.000 \\
\hline
\end{tabular}

$\left({ }^{*}\right.$ and ${ }^{* *}$ : Significant at the 0.05 and 0.01 probability levels respectively. ${ }^{\text {Ns }}$-non-significant)

(149.22\%) followed by LOK1 (146.96\%) upon comparison with treatment $T_{2}$ (PEG). The results of the present study is in agreement with Ahmad and Haddad (2011) in terms of significant induction in POX activity induced by silicon treatment as compared to control and PEG. Water deficit stress decreased POX activity which was contrary to the reports of Pratap and Sharma (2010) who observed an increase in POX activity at different osmotic gradients as compared to control.

The variety LOK1 showed highest CAT activity. $\mathrm{SiO}_{2}$ treatment led to an increase in catalase activity as seen in case of POX activity irrespective of water regime (Table 3 ). The interactive effect of $\mathrm{V} \times \mathrm{T}$ was found maximum in variety GW190 for $\mathrm{SiO}_{2}$ treatment while least activity was found in variety GW496 under water deficit $T_{2}$ treatment. The highest percent change in CAT activity was found in variety GW322 (159.86\%) followed by DL788-2 (138.06\%) when $\mathrm{SiO}_{2}+\mathrm{PEG}$ and PEG treatments were compared. A study conducted by Moldes et al. (2013) revealed that silicon altered CAT activity in roots and leaves of unstressed cotton plants. Gong et al. (2005) reported an increased CAT activity on silicon application. Our results are also supported by the findings of Gunes et al. (2008) which stated a decrease in CAT activity upon water deficit stress, which was improved by silicon application.

The results of correlation analysis under PEG stress and silicon treatment in wheat seedlings is shown in Table 4. The results revealed that enzymatic antioxidants had positive correlation $(P<0.01)$ with RWC and MSI. A negative correlation $(P<0.01)$ was found between oxidative stress factor like MDA and RWC, MSI, POX. Oxidative stress leads to a raised level of MDA, in turn the reactive oxygen species (ROS) is maintained by elevated content of enzymatic antioxidants. This is reflected by significant negative correlation between the same. In contrast to above results, proline showed negative correlation with almost all the parameters, except MDA. Negative correlation of proline may be due to the fact that there may be a rapid breakdown of proline upon relief of stress providing sufficient reducing agents 
supporting generation of ATP for recovery of stress and repairing of stress induced damages as revealed by Ashraf and Foolad (2007).

From the above results, silicon treatment was found to alleviate PEG induced water deficit stress. It seems to play an important role in moderating water status and also maintaining the cell membrane integrity/providing relief to membrane injury. Higher level of antioxidative enzymes content in $\mathrm{SiO}_{2}$ treated plants as compared with that of stressed plants states its role in relief of oxidative stress induced under unfavorable conditions. Also, this is a new approach with regards to foliar application of silicon to a large number of varieties and the results need to be validated in future by using varieties whose status with regards to tolerance or susceptibility is known.

\section{Acknowledgment}

The first author is thankful to the Indian Council of Agricultural Research, New Delhi for granting Senior Research Fellowship (Agric./Plant Sciences) for pursuing the Ph.D. programme.

\section{References}

Aebi, H.: Catalase in vitro. Method. Enzymol., 105, 121-126 (1984).

Ahmad, S.T. and R. Haddad: Study of silicon effects on antioxidant enzyme activities and osmotic adjustment of wheat under drought stress. Czech J. Genet. Plant, 47, 17-27 (2011).

Ahmed, M., F. U. Hassen, U. Qadeer and M. A. Aslam.: Silicon application and drought tolerance mechanism of sorghum. Afr. J. Agric. Res., 6, 594-607 (2011).

Ashraf, M. and M.R. Foolad: Role of glycine betaine and proline in improving plant abiotic stress resistance. Environ. Exp. Bot., 59, 206-216 (2007).

Bates, L.S.: Rapid determination of free proline for water stress studies. Plant Soil, 39, 205-207 (1973).

Bisswanger, H.: Practical Enzymology. Wiley-VCH Verlag and Co. KGaA, Boschstr, Weinheim, Germany (2011).

Blum, A.: Cell membrane stability as a measure of drought and heat tolerance in wheat. Crop Sci., 21, 45-47 (1981).

Buchanan, B., W. Gruissem and R. Jones.: Biochemistry and molecular biology of plants. Wiley (2002).

Chen, W., X. Yao, K. Cai and J. Chen. Silicon alleviates drought stress of rice plants by improving plant water status, photosynthesis and mineral nutrient absorption. Biol. Trace Elem. Res., 142, 67-76 (2011).

Elliott, C.L. and G.H. Snyder: Autoclave-induced digestion for the colorimetric determination of silicon in rice straw. J. Agric. Food Chem., 39, 1118-1119 (1991).

Gao, X., C. Zou, L. Wang and F. Zhang: Silicon decreases transpiration rate and conductance from stomata of maize plants. J. Plant Nutr., 29, 1637-1647 (2006).

Garg, B., J.P. Jaiswal, S. Misra, B.N. Tripathi and M. Prasad: A comprehensive study on dehydration-induced antioxidative responses during germination of Indian bread wheat cultivars collected from different agroclimatic zones. Physiol. Mol. Biol.
Plants, 18, 217-228 (2012).

Geravandi, M., E. Farshadfar and D. Kahrizi: Evaluation of some physiological traits as indicators of drought tolerance in bread wheat genotypes. Russ. J. Plant Physl., 58, 69-75 (2011).

Gong, H., X. Zhu, K. Chen, S. Wang and C. Zhang: Silicon alleviates oxidative damage of wheat plants in pots under drought. Plant Science, 169, 313-321 (2005).

Gunes, A., D.J. Pilbeam, A. Inal and S. Coban: Influence of silicon on sunflower cultivars under drought stress, I: Growth, antioxidant mechanisms and lipid peroxidation. Commun. Soil Sci.Plan., 39, 1885-1903 (2008).

Heath, R.I. and L. Packer: Photoperoxidation in isolated chloroplast. Kinetics and stochiometry of fatty acid peroxidation. Arch. Biochem. Biophys., 125, 189-198 (1968).

Hiscox, J.D. and G.F. Israelstam: A method for extraction of chloroplast from leaf tissue without maceration. Can. J. Botany, 57, 1332-1334 (1979).

Kumari, A. and R.K. Sairam: Moisture stress induced increases in the activity of enzymes of osmolytes biosynthesis are associated with stress tolerance in wheat genotypes. Indian J. Plant Physi., 18, 223-230 (2013).

Lowry, O.H., N.J. Rosebrough, A.L. Farr and R.J. Randall: Protein measurement with the folin phenol reagent. J. Biol. Chem., 193, 265-275 (1951).

Lutts, S., V. Majerus and J.M. Kinet: $\mathrm{NaCl}$ effects on proline metabolism in rice seedlings. Physiol. Plantarum, 105, 450-458 (1999).

Mauad, M., C.A.C. Crusciol, A.S. Nascente, H.G. Filho and G.P.P. Lima: Effects of silicon and drought stress on biochemical characteristics of leaves of upland rice cultivars. Rev. Ciencia Agron., 47, 532-539 (2016).

Moldes, C.A., O.F.L. Filho, J.S. Camina, S.G. Kiriachek, M.L. Molas and S.M. Tsai.: Assessment of the effect of silicon on antioxidative enzymes in cotton plants by multivariate analysis. J. Agric. Food Chem., 61, 11243-11249 (2013).

Nezhadahmadi, A., Z.H. Prodhan and G. Faruq: Drought tolerance in wheat. Sci. World J., 2013, (2013). (http://dx.doi.org/10.1155/ 2013/610721).

Pei, Z.F., D.F. Ming, D. Liu, G.L. Wan, X.X. Geng, H.J. Gong and W.J. Zhou: Silicon improves the tolerance to water-deficit stress induced by polyethylene glycol in wheat seedlings. Plant Growth Regul., 29, 106-115 (2010).

Pilon, C., R.P. Soratto, F. Broetto and A.M. Fernandes: Foliar or soil applications of silicon alleviate water deficit stress of potato plants. Agron. J., 106, 2325-2334 (2014).

Pilon, C., R.P. Soratto and L.A. Moreno: Effects of soil and foliar application of soluble silicon on mineral nutrition, gas exchange, and growth of potato plants. Crop Science, 53, 1605-1614 (2013).

Pratap, V. and Y.K. Sharma: Impact of osmotic stress on seed germination and seedling growth in black gram. J. Env. Biol., 31, 721-726 (2010).

Reddy, A.R., K.V. Chaitanya and M. Vivekanandan: Drought induced responses of photosynthesis and antioxidant metabolism in higher plants. J. Plant Physiol.,161, 1189-1202 (2004).

Sacala, E.: Role of silicon in plant resistance to water stress. J. Elem., 14, 619-630 (2009).

Sairam, R.K., K.V. Rao and G.C. Srivastava: Differential response of wheat genotypes to long term salinity stress in relation to oxidative stress, antioxidant activity and osmolyte concentration. Plant Science, 163, 1037-1046 (2002). 
Sairam, R.K. and G.C. Srivastava: Water stress tolerance of wheat (Triticum aestivum L.): Variations in hydrogen peroxide accumulation and antioxidant activity in tolerant and susceptible genotypes. J. Agron. Crop Sci., 186, 67-70 (2001).

Sayed, S.A. and M.A.A. Gadallah: Effects of silicon on Zea mays plants exposed to water and oxygen deficiency. Russ. J. Plant Physiol., 61, 460-466 (2014).

Shen, X., Y. Zhou, L. Duan, Z. Li, E. Eneji and J. Li: Silicon effects on photosynthetic and antioxidant parameters of soyabean seedlings under drought and ultraviolet-B radiation. J. Plant Physiol., 167, 1248-1252 (2010).

Soratto, R.P., C.A.C. Crusciol, G.S.A. Castro, C.H.M. Costa and J.F. Neto: Leaf application of silicic acid to white oat and wheat. Rev.
Bras. Cienc. Solo., 36, 1538-1544 (2012).

Stoilova, L.S., K. Demirevska, T. Petrova, N. Tsenov and U. Feller: Antioxidative protection and proteolytic activity in tolerant and sensitive wheat (Triticum aestivum L.) varieties subjected to longterm field drought. Plant Growth Regul., 58, 107-117 (2009).

Valifard, M., A. Moradshahi and B. Kholdebarin: Biochemical and physiological responses of two wheat cultivars to drought stress applied at seedling stage. JAST, 14, 1567-1578 (2012).

Wang, S.Y. and G.J. Galleta: Foliar application of potassium silicate induces metabolic changes in strawberry plants. J. Plant Nutr., 21, 157-167 (1998).

Weatherley, P.E.: Studies in the water relations on the cotton plant. I. The field measurement of water deficit in leaves. New Phytol., 49, 8187 (1950). 